\title{
Efficacy of telephone support as a tool for promoting daily physical activity in type 2 diabetic patients
}

Cristina Helena Ferreira Fonseca-Guedes ${ }^{\dagger}$, Samantha Souza Possa ${ }^{\dagger}$, Renato Fraga Righetti ${ }^{\dagger}$, Mariana Fernandes Jucá ${ }^{\dagger}$, Isabela Judith Martins Benseñor ${ }^{\dagger}$, Celso Ricardo Fernandes Carvalho ${ }^{\dagger}$, Milton Arruda Martins ${ }^{\dagger}$ and lolanda de Fátima Lopes Calvo Tibério ${ }^{\dagger *}$

*Correspondence: iocalvo@uol.com.br

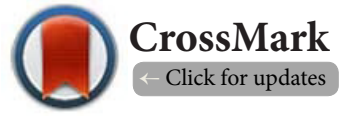

†These authors contributed equally to this work.

Department of Medicine, School of Medicine, University of São Paulo, São Paulo, Brazil.

\begin{abstract}
Background: Type 2 diabetes mellitus (T2DM) is a highly prevalent public health problem. Although there is strong evidence supporting the essential role of physical activity in the management of T2DM, the prescription of physical activity has limited success in promoting changes in behavior. The purpose of the present study was to evaluate the impact of phone call support, over the course of five weeks, as an incentive to promote walking in type 2 diabetic patients with poor glycemic control.

Methods: A total of 54 type 2 diabetic patients with poor glycemic control $\left(\mathrm{HbA}_{1 \mathrm{C}} \mathrm{Hg} \geq 8 \%\right.$ ) were enrolled in a randomized controlled clinical trial that was conducted at an outpatient clinic. The intervention patients received one telephone call per week for 5 weeks to encourage activity in the form of walking. Control patients did not receive phone calls. The number of steps each subject took was recorded weekly using pedometers.

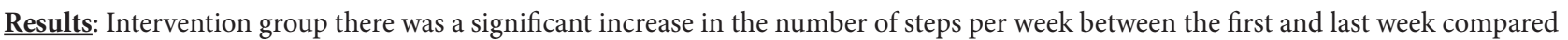
to the control group $(\mathrm{P}<0.001)$. The absolute risk reduction was $75 \%$, and it was necessary to provide phone call support for only three patients to obtain an increase in the number of the steps between the first and the last week of the study $(\mathrm{NNT}=3.0)$.

Conclusions: Our results suggest that the telephone call, a high cost-benefit approach, may be an efficient intervention for promoting physical activity improvement in type 2 diabetic patients with poor glycemic control.

Keywords: Pedometer, diabetes mellitus, physical activity, phone call support
\end{abstract}

\section{Introduction}

Type 2 diabetes mellitus (T2DM) represents a vast public health problem because T2DM patients display many risk factors and comorbidities that require complex care [1]. T2DM patients comprise approximately $90 \%$ of diabetes patients, and the incidence of type 2 diabetes is rising. In the US, for example, the incidence of T2DM doubled in the last 30 years, with the costs related to type 2 diabetes control varying from 2.5 to $15 \%$ of the total annual health spending in the country $[2,3]$. In addition, the life expectancy of diabetics is shortened by approximately 15 years, with the majority of these patients dying of macrovascular complications [4]. The overall goals and all options for drug therapy for T2DM patient management focus on controlling both hyperglycemia and the risk factors for it. In this context, therapy is focused on improving physical activity and dietary habits in all age groups [5].

There is strong evidence concerning the role of physical activity in the management of T2DM patients [5-7]. Current public health recommendations for physical activity are 30 min of moderate-intensity activity per day [8]. It was previously shown that, even in the presence of high caloric intake, performing habitual physical activity can prevent pathophysiological symptoms that result from physical inactivity [9]. Walking is the most popular leisure time activity [10], and walking intensity can be improved by using a pedometer $[11,12]$.

Patients with T2DM present with lower levels of physical activity compared to individuals of the same gender and age without the disease, most likely due to having obesity-related T2DM [13]. Additionally, it has been shown that even leisuretime physical activity reduces the risk of T2DM in patients with T2DM-associated risk factors [14]. These data emphasize the correlation between physical activity and diabetes.

Although daily physical activity is essential for the management of type 2 diabetic patients, its prescription as the single strategy for increasing physical activity, and consequently promoting behavior changes, has shown poor efficacy. The aim of the present study was to investigate the impact of phone call support as a tool for promoting the enhancement of daily physical activity during a period of 5 weeks in a group of type 2 diabetic patients with poor glycemic control $\left(A_{1 C} \geq 8 \%\right)$.

\section{Methods}

A total of 54 type 2 diabetic patients with poor glycemic control $\left(A_{1 C} \geq 8 \%\right)$ and at least one cardiovascular comorbidity (such 
Fonseca-Guedes et al. Journal of Diabetes Research \& Clinical Metabolism 2014,

as hypertension and/or dyslipidemia) were enrolled in a randomized controlled clinical trial that was conducted in the outpatient clinic of a tertiary university hospital in São Paulo, Brazil. The study was approved by the Ethics Committee of the Medical School at the University of São Paulo. The protocol was written according to Declaration of Helsinki and followed the guidelines for Good Clinical Practice (GCP) [15].

Subjects who received a T2DM diagnosis by the Clinical Hospital-Faculty of Medicine of the University São Paulo at least 1 year prior to the study and who accepted the participation offer and signed the written informed consent were included in the study. All subjects had to have a phone number to receive phone contacts from researchers and had to agree to use a pedometer for 6 weeks. In addition, all subjects had to be capable of recording their number of steps taken per day.

Study subjects who did not agree to sign the written informed consent, were unable to answer the questionnaire, did not have a phone number, did not agree to use the pedometer for 6 weeks and who were unable to record their number of steps taken per day in a notebook were excluded.

All enrolled patients were introduced to the importance of performing physical activity and maintaining glycemic control. They were treated for diabetes according to the accepted international guidelines (oral therapies included sulfonylureas $(n=12)$, metformin $(n=29)$, insulin $(n=29)$ and statins $(n=29)$ ). Medications and dosages were not changed during the study period and there were no group differences in oral therapy. The subjects also had other diseases, such as hypertension, dyslipidemia and osteoarthrosis (without major limitations for walking).

Each patient was interviewed by a trained researcher who utilized the following validated instruments: the Prime MD questionnaire to evaluate depression symptoms [16], the Comrey Personality Scales to define their personality profiles [17], the Functional Assessment of Chronic Illness Therapy (FACIT) questionnaire, wich analyzed aspects of quality of life [18], the transtheoretical model of behavior change of Prochaska [19], the IPAQ (International Physical Activity Questionnaire) to assess activity level [20] and a score based on the Brazilian Demographic Census to evaluate the socio-economic status [21]. Additionally, data concerning metabolic control and the number of comorbidities were obtained.

The trained researcher also obtained the following measurements: 1 . blood pressure measured using a digital sphygmomanometer after the participant rested in a seated position for $15 \mathrm{~min}$; 2 . weight-measured with light clothes (in $\mathrm{kg}$ ), without shoes; 3 . height measured in centimeters (cm); 4. waist circumference-measured with a steel tape and taken as the smallest circumference between the iliac crest and the lower border of the ribs (always under the clothes; and 5. body mass index-calculated as weight (in $\mathrm{kg}$ ) divided by height (in meters) squared.

The protocol design consisted of a seven-day baseline period during which the participants were asked not to change their physical activity habits followed by the 5-week intervention period. During the baseline period, all of the participants used the pedometer to record their step counts each day. All subjects were randomized into two groups: CG (control group) and IG (intervention group). The CG subjects received just one phone call after the first week (baseline week) orienting them to pedometer use for the subsequent 5 weeks. The IG subjects received phone calls (one phone call every 10 days) over the next 5 weeks encouraging them to increase their walking activity. This group also received hints (strategies) to help them achieve changes in their activity levels, including walking to shop, walking to the drugstore and walking their children to school. Others strategies included getting off the bus before the final destination or not using escalators in the subway or supermarket. These orientations were given always by the same researcher with the same arguments.

During the study period, the participants used the pedometer (Yamax Digiwalker step counter; SW-200 - Official Pedometer of American Volkssport Association) throughout the day, except for sleeping and bathing, and were trained regarding its placement and use. Pedometers provide a daily total of steps taken.

The information collected was transferred to a database and analyzed using SigmaStat software, Version 3.1 (SPSS Inc, Chicago, IL). Descriptive statistics characterized of the depression symptoms, personality profiles and quality of life measures. The parametric quantitative variables were described by their mean, standard error and t test. Non-parametric data were described using medians (25\%-75\% percentiles) and the Kruskal-Wallis test. The relative and absolute risks and the number needed to treat (NNT) were determined considering the response to the telephone call as incentive to increasing of the number of steps taken as defined event. A $P$ value $<0.05$ was considered significant.

\section{Results}

Fifty-four patients were enrolled in the study (20 IG and 35 CG). Of these patients, 48 completed the study (19 IG subjects and 29 CG subjects). Six patients (one IG subjects and five CG subjects) were excluded due to difficulties concerning their use of the pedometers or their recording of information in the patient diary.

There were no significant differences in either the total scores in each domain of the FACIT questionnaire for assessing quality of life, the IPAQ questionnaire for assessing activity level, Prochaska's transtheoretical model for changes in behavior and socioeconomic status ( $P>0.05$ for all comparisons).

Several confounding factors were also analyzed. Data obtained with the Prime MD questionnaire showed that there were no differences in the mean scores for depression symptoms (mean \pm EP: CG: $4.4 \pm 0.6 ;$ IG: $4.5 \pm 0.7$ ). There were no differences in personality profiles between the groups among the different domains.

At baseline, there were no significant differences between 
the groups for clinical, anthropometric and socio-demographic data $(P>0.05)$ (Table 1). The mean age \pm SE was: $58.8 \pm 1.6$ years old. Twenty-one subjects were men ( $60.7 \pm 2.9$ years old) and 33 were women $(57.8 \pm 1.8$ years old).

In the intervention group there was a significant increase in the number of steps per week between the first and last week compared to the control group $(P<0.001)$ (Table 2). The absolute risk reduction was $75 \%$, and it was necessary to provide phone call support for only three patients to obtain an increase in the number of the steps between the first and the last week of the study (NNT=3.0).

\section{Discussion}

In the present study, we showed that phone call support showed an absolute risk reduction of $75 \%$. In addition, it was necessary to make weekly phone calls during the 5 weeks for just three patients to obtain one positive response concerning the increase of the number of steps in the last week. There were no differences in the baseline values of all clinical, socio-demographic and anthropometric factors between the groups as well as for other possible interfering variables that could modify the response to the stimuli for improving walking activity.

It is already known that in short term interventions; the use of pedometers during physical training improves physical activity levels [22]. However, due to the need for low-cost strategies, the focus of the present study was on the analysis of the effectiveness of phone call support in enhancing physical activity levels. Despite the poor glycemic control among the patients in our study, we found a significant improvement of walking activity among the patients who received support through phone calls. In addition, this positive result was obtained even without the involvement of a trained professional.

Considering possible strategies for improving physical activity, Green et al., (2002) evaluated phone call support in patients receiving primary care. However, type 1 or type 2 diabetic patients with cardiovascular complications were excluded from the study. The authors suggested that this intervention was adequate to increase the level of physical activity [23].

More recently, Goodarzi et al., (2012) verified the impact of the use of short message service (SMS) via mobile phone for the maintenance of adequate levels of blood glucose, lipids, creatinine and $\mathrm{HbA}_{1} \mathrm{C}$ of T2DM patients. The authors found that SMS via mobile phone was also an effective intervention for this type of population [24].

The current study identified a significant increase in number of steps in the intervention group. Considering this results, we showed that the use of the pedometer and verbal stimuli by phone calls were effective in increasing the number of steps and, therefore, physical activity. The physical activity has been the mode traditionally prescribed for diabetes prevention and management. . It is known that the increment of the number of steps per day is a good target to use in interventions aiming increase of physical activity [25]. Only one week of aerobic training can improve whole-body insulin sensitivity in individuals

Table 1. Metabolic and anthropometric variables of 54 type 2 diabetes mellitus subjects.

\begin{tabular}{|c|c|c|c|}
\hline & Control group & Intervention group & P value \\
\hline Age-mean $\pm S E$ & $58.8 \pm 1.56$ & $53.4 \pm 1.6$ & 0.27 \\
\hline BMI $\left(\mathrm{kg} / \mathrm{m}^{2}\right)-$ mean \pm SE & $29.8 \pm 0.9$ & $30.1 \pm 1.3$ & 0.82 \\
\hline Waist circumference ${ }^{3} 90 \mathrm{~cm}-\mathrm{mean} \pm \mathrm{SE}$ & $102.5 \pm 2.9$ & $106.1 \pm 6.9$ & 0.5 \\
\hline Waist circumference ${ }^{3} 80 \mathrm{~cm}-$ mean $\pm S E$ & $101.6 \pm 3.6$ & $97.8 \pm 4.0$ & 0.5 \\
\hline Systolic arterial pressure (mmHg)-median ( $25 \%-75 \%$ percentile) & $133(120-141)$ & $133(121-150)$ & 0.95 \\
\hline Diastolic arterial pressure $(\mathrm{mmHg})$-mean $\pm \mathrm{SE}$ & $74.3 \pm 2.3$ & $75.2 \pm 1.6$ & 0.79 \\
\hline $\mathrm{LDL}(\mathrm{mg} / \mathrm{dL})-\mathrm{mean} \pm \mathrm{SE}$ & $97.3 \pm 6.1$ & $89.0 \pm 5.0$ & 0.35 \\
\hline $\mathrm{HDL}(\mathrm{mg} / \mathrm{dL})-$ mean $\pm \mathrm{SE}$ & $54.6 \pm 3.7$ & $61.6 \pm 3.6$ & 0.24 \\
\hline Triglycerides $(\mathrm{mg} / \mathrm{dl})$-median $(25 \%-75 \%$ percentile $)$ & $122.5(93-174)$ & $112(70.7-153)$ & 0.34 \\
\hline
\end{tabular}

*BMI=body mass index

${ }^{\dagger} \mathrm{LDL}=$ low density lipoprotein

${ }^{*} \mathrm{HDL}=$ high density lipoprotein

Table 2. Mean and median (25\%-75\%) step numbers from pedometers between the basal week and the final week.

\begin{tabular}{llll}
\hline & Control group (n=29) & Intervention group (n=19) & P value \\
\hline Basal week median (25\%-75\% percentile) & $4911.5(3669.5-7255.0)$ & $6184.2(5035.1-9574.8)$ & 0.08 \\
Last week median (25\%-75\% percentile) & $4343.5(2755.0-6929.3)$ & $8813.7(6604.9-11113.5)$ & 0.001 \\
Basal week $\boldsymbol{v s}$ last week median (\% change) & $-11,56$ & 42,51 & $<0.001$ \\
\hline
\end{tabular}


Fonseca-Guedes et al. Journal of Diabetes Research \& Clinical Metabolism 2014,

with T2DM [26]. Moderate and vigorous aerobic training improve insulin sensitivity [27], albeit for only a period of hours to days [28], but a lesser intensity may also improve insulin action to some degree [27]. Training can enhance the responsiveness of skeletal muscles to insulin with increased expression and/or activity of proteins involved in glucose metabolism and insulin signaling. Moderate training may increase glycogen synthase activity and GLUT4 protein expression but not insulin signaling [29]. Fat oxidation is also a key aspect of improved insulin action, and training increases lipid storage in muscles and fat oxidation capacity [30].

It has also been previously shown that walking 2000 steps more than usual can prevent gradual weight gain [31]. Based on the multiple benefits between weight loss and T2DM, including prevention of cardiovascular events, reduction of the use of medications (due to the improvement of glycaemic control), of microvascular complications [32], as well as mortality [33], it is consequently concluded that increment of the level of physical activity enhanced with the increase of number of steps is clinically very useful. Thus, although in the present study we did not intend to evaluate the clinical outcomes of increasing the number of steps among T2DM patients with the phone calls, we have demonstrated a median increase of more than 2000 steps with this way of intervention, confirming the effectiveness of the technique in management of the T2DM population.

Plotnikoff et al., (2013), however, found no significant improvement in the level of physical activity or hemoglobin A1C in T2DM patients using distance education with print-based materials alongside pedometer use and telephone counseling, although this intervention did increase the steps counts between women [34].

Although IPAQ is considered adequate to show the activity level of the patients, the pedometers are able to give objective and quantitative data. Furthermore, in the present study we did not find any significant difference between the groups related to personality factors. This result may reduce the necessity for an extremely individualized treatment that takes aspects of peoples' personalities into account, although the small sample size impairs the affirmation of this hypothesis.

We used the transtheoretical behavior change questionnaire developed by Prochaska and DiClemente (1992) to clarify the phase of behavior change of our patients and to determine the influence of these conditions on the studied outcome [19]. In accordance with our study, Ishiii et al., (2007) performed a controlled study using this model to improve the physical activity of 38 people without any prior disease. However, it is important to note that this study was underpowered to demonstrate an impact of "readiness to change" on outcomes. Thus, the negative finding could be a result of low power. The authors did not find any differences concerning the phase in which the patients were classified according to the Prochaska questionnaire [35]. It is probable that during a short intervention period, the impact of the phase of behavior may be less significant than for a longer time, when these behavior aspects need to be considered.

It is also well know that depression is associated with decreased self-care, including diet, behavior changes, and drug therapy adherence [36]. In the present study, we did not find any differences between the groups related to depression diagnoses $(P>0.05)$. Finally, there were no differences concerning the evaluation of quality of life using the FACTI, either in the total score or in individual domains for baseline and post intervention analysis.

The present study had some limitations. The reduced number of patients enrolled might influence the multivariate logistic regression results. Studies including more patients for a longer time than the present study need to be performed to clarify these points. Another important limitation is that patients in the IG (1) and CG (5) were excluded from the study due to being unable to complete the diary, thus precluding any comparison between the "completers versus non-completers" in the intention-to-treat analysis.

\section{Conclusions}

In conclusion, phone call support was an efficient intervention for promoting walking in type 2 diabetic patients with poor glycemic control, constituting an interesting low-cost intervention for the prevention of complications in this group of patients.

\section{Competing interests}

The authors declare that they have no competing interests.

\section{Authors' contributions}

\begin{tabular}{|l|c|c|c|c|c|c|c|c|}
\hline $\begin{array}{l}\text { Authors' } \\
\text { contributions }\end{array}$ & CFF & SSP & RFR & MFJ & IMB & CFC & MAM & IFT \\
\hline $\begin{array}{l}\text { Research concept } \\
\text { and design }\end{array}$ & $\checkmark$ & -- & -- & $\checkmark$ & $\checkmark$ & -- & -- & $\checkmark$ \\
\hline $\begin{array}{l}\text { Collection and/or } \\
\text { assembly of data }\end{array}$ & $\checkmark$ & -- & -- & $\checkmark$ & $\checkmark$ & -- & -- & -- \\
\hline $\begin{array}{l}\text { Data analysis and } \\
\text { interpretation }\end{array}$ & $\checkmark$ & $\checkmark$ & $\checkmark$ & -- & -- & -- & -- & $\checkmark$ \\
\hline Writing the article & $\checkmark$ & $\checkmark$ & $\checkmark$ & -- & -- & -- & $\checkmark$ & -- \\
\hline $\begin{array}{l}\text { Critical revision of } \\
\text { the article }\end{array}$ & -- & -- & -- & -- & -- & $\checkmark$ & $\checkmark$ & $\checkmark$ \\
\hline $\begin{array}{l}\text { Final approval of } \\
\text { article }\end{array}$ & $\checkmark$ & $\checkmark$ & $\checkmark$ & $\checkmark$ & $\checkmark$ & $\checkmark$ & $\checkmark$ & $\checkmark$ \\
\hline Statistical analysis & $\checkmark$ & $\checkmark$ & $\checkmark$ & -- & -- & -- & -- & - \\
\hline
\end{tabular}

\section{Acknowledgement}

The authors are grateful for Brazilian Scientific Agencies: Conselho Nacional de Desenvolvimento Científico e Tecnológico (CNPq), Fundação de Amparo à Pesquisa do Estado de São Paulo (FAPESP) and Laboratório de Investigação Médica do Hospital das Clínicas da Faculdade de Medicina da Universidade de São Paulo (LIM 20) for their financial support.

\section{Publication history}

EIC: Geoffrey Burnstock, University College London, UK. Received: 06-Jan-2014 Final Revised: 19-Apr-2014 Accepted: 01-May-2014 Published: 14-May-2014

\section{References}

1. Davies MJ. The prevention of type 2 diabetes mellitus. Clin Med. 2003; 
3:470-4. | Article | PubMed

2. Ettaro L, Songer TJ, Zhang P and Engelgau MM. Cost-of-illness studies in diabetes mellitus. Pharmacoeconomics. 2004; 22:149-64. | Article | PubMed

3. Fox CS, Pencina MJ, Meigs JB, Vasan RS, Levitzky YS and D'Agostino RB, Sr. Trends in the incidence of type 2 diabetes mellitus from the 1970s to the 1990s: the Framingham Heart Study. Circulation. 2006; 113:2914-8. | Article | PubMed

4. Geiss LS, Pan L, Cadwell B, Gregg EW, Benjamin SM and Engelgau MM. Changes in incidence of diabetes in U.S. adults, 1997-2003. Am J Prev Med. 2006; 30:371-7. | Article | PubMed

5. Sigal RJ, Kenny GP, Boule NG, Wells GA, Prud'homme D, Fortier M, Reid RD, Tulloch H, Coyle D, Phillips P, Jennings A and Jaffey J. Effects of aerobic training, resistance training, or both on glycemic control in type 2 diabetes: a randomized trial. Ann Intern Med. 2007; 147:357-69. | Article | PubMed

6. Miles MP, Pearson SD, Andring JM, Kidd JR and Volpe SL. Effect of carbohydrate intake during recovery from eccentric exercise on interleukin-6 and muscle-damage markers. Int I Sport Nutr Exerc Metab. 2007; 17:507-20. | PubMed

7. Eves ND and Plotnikoff RC. Resistance training and type 2 diabetes: Considerations for implementation at the population level. Diabetes Care. 2006; 29:1933-41. | Article | PubMed

8. Blair SN, LaMonte MJ and Nichaman MZ. The evolution of physical activity recommendations: how much is enough? Am J Clin Nutr. 2004; 79:913S-920S. | Article | PubMed

9. Krogh-Madsen R, Pedersen M, Solomon TP, Knudsen SH, Hansen LS, Karstoft K, Lehrskov-Schmidt L, Pedersen KK, Thomsen C, Holst JJ and Pedersen BK. Normal physical activity obliterates the deleterious effects of a high-caloric intake. J Appl Physiol (1985). 2014; 116:231-9. | Article I PubMed

10. Chan CB, Spangler E, Valcour J and Tudor-Locke C. Cross-sectional relationship of pedometer-determined ambulatory activity to indicators of health. Obes Res. 2003; 11:1563-70. | Article | PubMed

11. Johnson ST, Boule NG, Bell GJ and Bell RC. Walking: a matter of quantity and quality physical activity for type $\mathbf{2}$ diabetes management. Appl Physiol Nutr Metab. 2008; 33:797-801. | Article | PubMed

12. Araiza P, Hewes H, Gashetewa C, Vella CA and Burge MR. Efficacy of a pedometer-based physical activity program on parameters of diabetes control in type 2 diabetes mellitus. Metabolism. 2006; 55:1382-7. | Article | PubMed

13. Fagour C, Gonzalez C, Pezzino S, Florenty S, Rosette-Narece M, Gin H and Rigalleau V. Low physical activity in patients with type 2 diabetes: the role of obesity. Diabetes Metab. 2013; 39:85-7. | Article | PubMed

14. Brouwer BG, van der Graaf Y, Soedamah-Muthu SS, Wassink AM and Visseren FL. Leisure-time physical activity and risk of type $\mathbf{2}$ diabetes in patients with established vascular disease or poorly controlled vascular risk factors. Diabetes Res Clin Pract. 2010; 87:372-8. | Article | PubMed

15. Harriss DJ and Atkinson G. International Journal of Sports Medicine ethical standards in sport and exercise science research. Int I Sports Med. 2009; 30:701-2. | Article | PubMed

16. Spitzer RL, Williams JB, Kroenke K, Linzer M, deGruy FV, 3rd, Hahn SR, Brody $D$ and Johnson JG. Utility of a new procedure for diagnosing mental disorders in primary care. The PRIME-MD 1000 study. JAMA. 1994; 272:1749-56. | Article | PubMed

17. Wilcox WW and Wenger WK. Reliability and stability of the Comrey Personality Scales in a clinical setting. J Clin Psychol. 1978; 34:555-7. | Article | PubMed

18. Vartanian JG, Carvalho AL, Yueh B, Furia CL, Toyota J, McDowell JA, Weymuller EA, Jr. and Kowalski LP. Brazilian-Portuguese validation of the University of Washington Quality of Life Questionnaire for patients with head and neck cancer. Head Neck. 2006; 28:1115-21. | Article | PubMed

19. Prochaska JO and DiClemente CC. Stages of change in the modification of problem behaviors. Prog Behav Modif. 1992; 28:183-218. | PubMed

20. Hallal PC and Victora CG. Reliability and validity of the International Physical Activity Questionnaire (IPAQ). Med Sci Sports Exerc. 2004; 36:556. | Article | PubMed

21. Critério de Classificação Econômica Brasil (CCEB). Associação Brasileira de Empresas de Pesquisa 2008. I Pdf
22. Funk $M$ and Taylor EL. Pedometer-based walking interventions for freeliving adults with type 2 diabetes: a systematic review. Curr Diabetes Rev. 2013; 9:462-71. | Article | PubMed

23. Green BB, McAfee T, Hindmarsh M, Madsen L, Caplow M and Buist D. Effectiveness of telephone support in increasing physical activity levels in primary care patients. Am J Prev Med. 2002; 22:177-83. | Article | PubMed

24. Goodarzi M, Ebrahimzadeh I, Rabi A, Saedipoor B and Jafarabadi MA. Impact of distance education via mobile phone text messaging on knowledge, attitude, practice and self efficacy of patients with type 2 diabetes mellitus in Iran. J Diabetes Metab Disord. 2012; 11:10. | Article | PubMed Abstract | PubMed Full Text

25. Wyatt HR, Peters JC, Reed GW, Barry M and Hill JO. A Colorado statewide survey of walking and its relation to excessive weight. Med Sci Sports Exerc. 2005; 37:724-30. | Article | PubMed

26. Winnick JJ, Sherman WM, Habash DL, Stout MB, Failla ML, Belury MA and Schuster DP. Short-term aerobic exercise training in obese humans with type 2 diabetes mellitus improves whole-body insulin sensitivity through gains in peripheral, not hepatic insulin sensitivity. J Clin Endocrinol Metab. 2008; 93:771-8. | Article | PubMed Abstract | PubMed Full Text

27. Houmard JA, Tanner CJ, Slentz CA, Duscha BD, McCartney JS and Kraus WE. Effect of the volume and intensity of exercise training on insulin sensitivity. J Appl Physiol (1985). 2004; 96:101-6. | Article | PubMed

28. King DS, Baldus PJ, Sharp RL, KesI LD, Feltmeyer TL and Riddle MS. Time course for exercise-induced alterations in insulin action and glucose tolerance in middle-aged people. J Appl Physiol (1985). 1995; 78:17-22. | Article | PubMed

29. O'Gorman DJ, Karlsson HK, McQuaid S, Yousif O, Rahman Y, Gasparro D, Glund S, Chibalin AV, Zierath JR and Nolan JJ. Exercise training increases insulin-stimulated glucose disposal and GLUT4 (SLC2A4) protein content in patients with type 2 diabetes. Diabetologia. 2006; 49:2983-92. | Article I PubMed

30. Goodpaster BH, Katsiaras A and Kelley DE. Enhanced fat oxidation through physical activity is associated with improvements in insulin sensitivity in obesity. Diabetes. 2003; 52:2191-7. | Article | PubMed

31. Hill JO, Wyatt HR, Reed GW and Peters JC. Obesity and the environment: where do we go from here? Science. 2003; 299:853-5. | Article | PubMed

32. Wilding JP. The importance of weight management in type 2 diabetes mellitus. Int I Clin Pract. 2014. [Epub ahead of print]. | Article | PubMed

33. Church TS, LaMonte MJ, Barlow CE and Blair SN. Cardiorespiratory fitness and body mass index as predictors of cardiovascular disease mortality among men with diabetes. Arch Intern Med. 2005; 165:211420. | Article | PubMed

34. Plotnikoff RC, Karunamuni N, Courneya KS, Sigal RJ, Johnson JA and Johnson ST. The Alberta Diabetes and Physical Activity Trial (ADAPT): a randomized trial evaluating theory-based interventions to increase physical activity in adults with type 2 diabetes. Ann Behav Med. 2013; 45:45-56. | Article | PubMed

35. Ishii A, Nakiri M, Nagatomi K, Tsuji Y, Hoshiko M, Yamaguchi Y, Muramoto $J$ and Ishitake T. Effect of a physical activity improvement program using the transtheoretical model at a small-scale company. Kurume Med J. 2007; 54:1-8. | Article | PubMed

36. DiMatteo MR, Lepper HS and Croghan TW. Depression is a risk factor for noncompliance with medical treatment: meta-analysis of the effects of anxiety and depression on patient adherence. Arch Intern Med. 2000; 160:2101-7. | Article | PubMed

\section{Citation:}

Fonseca-Guedes CHF, Possa SS, Righetti RF, Jucá MF, Benseñor IJM, Carvalho CRF, Martins MA and Tibério IdFLC. Efficacy of telephone support as a tool for promoting daily physical activity in type 2 diabetic patients. J Diab Res Clin Met. 2014; 3:6. http://dx.doi.org/10.7243/2050-0866-3-6 